1 Mårdh P-A, Ripa T, Svensson L, Weström L. Chlamydia trachomatis infection in patients with acute salpingitis. N EnglJ Med 1977;296:1377-9.

2 Weström L. Incidence, prevalence, and trends of acute pelvic inflammatory disease and its consequences in industrialized countries. Am J Obstet Gynecol 1980;138:880-92.

3 Padian NS, Washington E. Pelvic inflammatory disease: a brief overview. Ann Epidemiol 1994;4:128-32.

4 Chow N, Yonekura ML, Richwald GA, Greenland S, Sweet RL, Schachter $\mathrm{J}$. The association between Chlamydia trachomatis and ectopic pregnancy: a matched-pair, case-control study. JAMA 1990;263:3164-7.

5 Coste J, Laumon B, Brémond A, Collet P, Job-Spira N. Sexually transmitted diseases as major causes of ectopic pregnancy: results from a large case-control study in France. Fertil Steril 1994;62:289-95.

6 Taylor-Robinson D. Chlamydia trachomatis and sexually transmitted disease. $B M J$ 1994:308:150-1.

7 National Board of Health and Welfare. Anonymous Chlamydial infection-preventive measures. General recommendations from the National Board of Health and Welfare. Stockholm: National Board of Health and Welfare, 1990

8 Herrmann B, Egger M. Genital Chlamydia trachomatis infections in Uppsala county, Sweden 1985-1993: declining rates for how much longer? Sex Transm Dis 1995;22:253-60.

9 Kamwendo F, Forslin L, Bodin L, Danielsson D. Decreasing incidences of gonorrhoea- and chlamydia-associated acute pelvic inflammatory disease: a 25-year study from an urban area of central Sweden. Sex Transm Dis 1995;23:384-91.

10 Control of Infectious Diseases Act 1988. Stockholm: Ministry of Health, 1988: 1472. [Swedish code of law.]

11 Robinson AJ, Greenhouse P. Prevention of recurrent pelvic infection by contact tracing: a commonsense approach. $\mathrm{Br} J$ Obstet Gynaecol 1996;103:859-61.

12 Ripa KT, Mårdh P-A. Cultivation of Chlamydia trachomatis in cycloheximide treated McCoy cells. J Clin Microbiol 1977;6:328-31.
13 Cates W, Wasserheit JN. Genital chlamydial infections: epidemiology and reproductive sequelae. Am J Obstet Gynecol 1991;164:1771-81.

14 Cates W, Rolfs RT, Aral SO. Sexually transmitted diseases, pelvic inflammatory disease, and infertility: an epidemiologic update. Epidemiol Rev $1990 ; 12: 199-221$.

15 Xiong X, Buekens P, Wollast E. IUD use and the risk of ectopic pregnancy: a meta-analysis of case-control studies. Contraception 1995;52:23-34.

16 Franks AL, Beral V, Cates W, Hogue CJR. Contraception and ectopic pregnancy risk. Am J Obstet Gynecol 1990;163:1120-3.

17 Skjeldestad FE, Kendrick JS, Atrash HK, Daltveit AK. Increasing incidence of ectopic pregnancy in one Norwegian county: a population based study, 1970-1993. Acta Obstet Gynecol Scand 1997;76:159-65.

18 Chow W-H, Daling JR, Cates W, Greenberg RS. Epidemiology of ectopic pregnancy. Epidemiol Rev 1987;9:70-94.

19 Piantadosi S, Byar DP, Green SB. The ecological fallacy. Am J Epidemiol 1988; $127: 893-904$

20 Susser M. The logic in ecological. I. The logic of analysis. Am J Pub Health 1994;84:825-9.

21 Scholes D, Stergachis A, Heidrich FE, Andrilla H, Holmes KK, Stamm WE. Prevention of pelvic inflammatory disease by screening for cervical chlamydia infection. N Engl J Med 1996;334:1362-6.

22 Hillis SD, Nakashima A, Amsterdam L, Pfister J, Vaughn M, Addiss D, et al. The impact of a comprehensive chlamydia prevention program in Wisconsin. Fam Plann Perspect 1995;27:108-11.

23 Addiss DG, Vaughin ML, Ludka D, Pfister J, Davis JP. Decreased prevalence of Chlamydia trachomatis infection associated with a selective screening program in family planning clinics in Wisconsin. Sex Transm Dis 1993;20:28-34.

24 Johnson AM, Wadsworth J, Wellings K, Field J. Sexual attitudes and lifestyles. Oxford: Blackwell Scientific, 1994.

(Accepted 12 February 1998)

\title{
Blood pressure and mortality in elderly people aged 85 and older: community based study
}

\author{
Hendriek C Boshuizen, Gerbrand J Izaks, Stef van Buuren, Gerard J Ligthart
}

\section{TNO Prevention and Health, Division of Public Health and \\ Prevention, Leiden, \\ Netherlands \\ Hendriek C \\ Boshuizen, \\ epidemiologist \\ Stef van Buuren, \\ statistician \\ Section of \\ Gerontology and \\ Geriatrics, \\ Department of \\ General Internal \\ Medicine, Leiden \\ University Medical \\ Centre, Leiden \\ Gerbrand J Izaks, research fellow \\ Gerard J Ligthart, \\ associate professor \\ Correspondence to: \\ Dr Boshuizen \\ HC.Boshuizen@ \\ PG.TNO.NL}

BMJ 1998;316:1780-4

\begin{abstract}
Objective: To determine whether the inverse relation between blood pressure and all cause mortality in elderly people over 85 years of age can be explained by adjusting for health status, and to determine whether high blood pressure is a risk factor for mortality when the effects of poor health are accounted for.

Design: 5 to 7 year follow up of community residents aged 85 years and older.

Setting: Leiden, the Netherlands.

Subjects: 835 subjects whose blood pressure was recorded between 1987 and 1989.

Main outcome measure: All cause mortality.

Results: An inverse relation between blood pressure and all cause mortality was observed. For diastolic blood pressure crude 5 year all cause mortality decreased from $88 \%$ (52/59) $(95 \%$ confidence interval $79 \%$ to $95 \%$ ) in those with diastolic blood pressures $<65 \mathrm{~mm} \mathrm{Hg}$ to $59 \%(27 / 46)(44 \%$ to $72 \%)$ in those with diastolic pressures $>100 \mathrm{~mm} \mathrm{Hg}$. For systolic blood pressure crude 5 year all cause mortality decreased from $85 \%(95 / 112)(78 \%$ to $91 \%)$ in those with systolic pressures $<125 \mathrm{~mm} \mathrm{Hg}$ to $59 \%(13 / 22)$ (38\% to $78 \%$ ) in those with systolic pressures $>200 \mathrm{~mm} \mathrm{Hg}$. This decrease was no longer significant after adjustment for indicators of poor health. No relation existed between blood pressure and mortality from cardiovascular causes or stroke after adjustment for age and sex, but after adjustment for age, sex, and indicators of poor health there was a
\end{abstract}

positive relation between diastolic blood pressure and mortality from both cardiovascular causes and stroke. Conclusion: The inverse relation between blood pressure and all cause mortality in elderly people over 85 is associated with health status.

\section{Introduction}

In western societies blood pressure rises with age. It is not clear if this is the result of a pathological process that needs treatment or if it is part of the natural ageing process. Treating hypertension helps prevent stroke and coronary heart disease in middle aged and elderly people younger than 80. In two trials, however, no benefit of treatment was observed in subjects aged 80 and older. $^{12}$ Treating isolated systolic hypertension does not reduce all cause mortality in this age group, although it prevents stroke and heart failure. ${ }^{34}$

Since the number of subjects aged 80 and older included in these trials is small, evidence from observational studies may help in deciding whether to treat hypertension in patients at this age. Previous observational studies comprised of people aged 80 and older have found no relation between blood pressure and mortality, ${ }^{5}$ and a U shaped relation, ${ }^{6}$ or even an inverse relation in which higher blood pressure was associated with lower mortality. ${ }^{7-9}$ However, adjustment for confounding factors was made in only one study ${ }^{9}$; in this study only 35 deaths occurred in those aged over 80 .

To determine whether the relation between blood pressure and all cause mortality differs in elderly people older than 85 as compared with younger 
elderly people and to see whether this relation can be explained by poorer health among those with low blood pressure, we analysed the relation between blood pressure and mortality in a 5 to 7 year study of a cohort of residents of Leiden aged 85 and over; 621 deaths occurred and extensive data on health status at baseline were available.

\section{Subjects and methods}

The Leiden 85 plus study is a community based study that was designed to investigate the association between HLA and life expectancy. ${ }^{10}$ It contains data on all people aged 85 and over who lived in Leiden on 1 December 1986. There were 1236 cohort members eligible to participate in the study. Of these, 956 agreed to participate, 218 died before they could be visited, 59 declined to cooperate, 2 emigrated, and 1 was not interviewed in error; thus, $94 \%$ of all living subjects participated.

\section{Data collection}

Subjects were visited at their homes between January 1987 and May 1989 by a doctor. After obtaining verbal informed consent, the doctor recorded their age, sex, the country of origin of their parents and their marital status. The doctor also asked about the subject's medical history, including any drugs they were taking. If the subject was not able to provide the information, it was obtained from a relative or a carer. Medical records were reviewed for patients living in nursing homes. The method of validating a subject's medical history has been reported..$^{11} \mathrm{~A}$ minimental state examination ${ }^{12}$ was performed, and a venous blood sample was collected after permission was obtained. At the end of the interview, blood pressure was measured once with a mercury sphygmomanometer in 835 participants. Participants were seated while blood pressure was measured or supine in the few cases where the participant was bedridden. The reading was rounded up to the nearest $5 \mathrm{~mm} \mathrm{Hg}$ as is common clinical practice in the Netherlands. Diastolic pressure was not able to be measured in five subjects.

\section{Mortality data}

Data on mortality were collected from the municipal register or from the nursing home. For this paper subjects were followed until 1 March 1994. Preliminary analysis of data from a longer follow up period showed similar results. The cause of death was obtained by linking the number of the death certificate to the primary cause of death as coded by a physician from the Dutch Bureau of Statistics. Causes of death ${ }^{13}$ were categorised as stroke (ICD-9 codes 430-438), ischaemic heart disease (410-414), all cardiovascular disorders (390-459), cancer (140-239), infection (010-018, 038, $137-137.4,460-466.1,475,480-487.8,510,513.0-$ $513.1,590,599)$, and all other causes. In the analyses of specific causes of death follow up information until 1 October 1996 was used.

\section{Statistical analysis}

Crude data are presented as 5 year all cause mortality (survival time counted from the time of the home visit) for which 95\% confidence intervals were calculated using arc sin transformation. For multivariate analysis the Cox proportional hazards model was used, and age and sex were used as stratifying variables. To examine the shape of the relation between blood pressure and all cause mortality, blood pressure was modelled as a categorical covariate. To test whether a positive or negative linear relation existed between blood pressure and all cause or specific mortality, blood pressure was entered as a continuous covariate. Other covariates were selected either because they are medically important or because they significantly increased the fit of the model.

Continuous variables with a non-linear influence on mortality were modelled by adding quadratic terms. Checking the model showed that the hazard ratios for different blood pressures decreased as the length of time a subject was followed increased. Statistical models that incorporated this time dependency, however, yielded results that were similar to those that assumed a proportional hazard. For simplicity, we present the results of the proportional hazard model. Two covariates with mainly short term effects on

Table 1 Characteristics of 830 participants aged 85 and older by diastolic blood pressure. Values are numbers (percentages) unless indicated otherwise

\begin{tabular}{|c|c|c|c|c|c|c|c|c|}
\hline & \multicolumn{6}{|c|}{ Diastolic blood pressure $(\mathrm{mm} \mathrm{Hg})$} & \multirow[b]{2}{*}{$P$ value } & \multirow[b]{2}{*}{ All subjects } \\
\hline & $50-60$ & $65-70$ & $75-80$ & $85-90$ & $95-100$ & $>100$ & & \\
\hline Mean (SD) age (years) & $90(3)$ & $90(3)$ & $90(3)$ & $89(2)$ & $90(3)$ & $89(3)$ & 0.003 & $90(3)$ \\
\hline Men & $18 / 59(31)$ & $44 / 124(36)$ & $69 / 251(28)$ & $52 / 224(23)$ & $32 / 126(25)$ & $4 / 46(9)$ & 0.002 & $219 / 830(26)$ \\
\hline Able to eat, wash, and dress without help & $33 / 57(58)$ & $83 / 122(68)$ & $175 / 248(71)$ & $174 / 222(78)$ & $101 / 125(81)$ & $36 / 45(80)$ & 0.0001 & $602 / 819(74)$ \\
\hline $\begin{array}{l}\text { Mean (SD) score on minimental state } \\
\text { examination* }\end{array}$ & $20(7)$ & $23(7)$ & $24(7)$ & $25(6)$ & $25(6)$ & $27(5)$ & $<0.0001$ & $24(6)$ \\
\hline Mean serum albumin $(\mathrm{g} / \mathrm{l})$ & 39 & 40 & 41 & 41 & 41 & 42 & $<0.0001$ & 41 \\
\hline \multicolumn{9}{|l|}{ Medical history } \\
\hline Heart disease (excluding hypertension) & $22 / 54(41)$ & $32 / 122(26)$ & $74 / 241(31)$ & $53 / 218(24)$ & $28 / 122(23)$ & $6 / 45(13)$ & 0.03 & $215 / 802(27)$ \\
\hline Stroke & $4 / 54(7)$ & $18 / 123(15)$ & $31 / 244(13)$ & $27 / 220(12)$ & $19 / 122(16)$ & $3 / 45(7)$ & 0.90 & $102 / 808(13)$ \\
\hline Diabetes mellitus & $9 / 54(17)$ & 13/122 (11) & $30 / 241(12)$ & $26 / 219(12)$ & $11 / 122(9)$ & $4 / 45(9)$ & 0.23 & $93 / 803(12)$ \\
\hline Cancer & $4 / 54(7)$ & $12 / 123(10)$ & $19 / 241(8)$ & $9 / 219(4)$ & $2 / 122(2)$ & $1 / 45(2)$ & 0.002 & $47 / 804(6)$ \\
\hline \multicolumn{9}{|l|}{ Drug use } \\
\hline Using diuretics: & $29 / 58(50)$ & $41 / 121(34)$ & $106 / 245(43)$ & $90 / 221(41)$ & $45 / 125(36)$ & $17 / 46(37)$ & 0.33 & $328 / 816(40)$ \\
\hline Potassium sparing diuretics & $8 / 58(14)$ & 23/121 (19) & $52 / 245(21)$ & $51 / 221(23)$ & $18 / 125(14)$ & $8 / 46(17)$ & 0.95 & $160 / 816(20)$ \\
\hline Using glycosides & $16 / 58(28)$ & 20/121 (17) & $42 / 245(17)$ & $38 / 221(17)$ & $19 / 125(15)$ & $2 / 46(4)$ & 0.02 & $137 / 816(17)$ \\
\hline Using bronchodilators & $6 / 58(10)$ & $2 / 121(2)$ & $12 / 245(5)$ & $14 / 221(6)$ & $1 / 125(1)$ & $3 / 46(7)$ & 0.41 & $38 / 816(5)$ \\
\hline
\end{tabular}

*Scores range from 0 to $30 .{ }^{12}$ 
Table 2 Crude 5 year all cause mortality among 835 participants aged 85 and older by systolic blood pressure and among 830 participants aged 85 and older by diastolic blood pressure. Diastolic pressure could not be measured in five participants. Values are numbers (percentages; $95 \%$ confidence intervals)

\begin{tabular}{|c|c|c|c|c|}
\hline \multirow{2}{*}{$\begin{array}{l}\text { Blood pressure } \\
(\mathrm{mm} \mathrm{Hg})\end{array}$} & \multicolumn{2}{|c|}{ All participants } & \multicolumn{2}{|c|}{$\begin{array}{l}\text { Participants not using } \\
\text { antihypertensive drugs }\end{array}$} \\
\hline & No & 5 year mortality & No & 5 year mortality \\
\hline \multicolumn{5}{|l|}{ Systolic: } \\
\hline $90-120$ & 112 & 95 (85; 78 to 91$)$ & 57 & $46(81 ; 70$ to 90$)$ \\
\hline $125-140$ & 222 & $166(75 ; 69$ to 80$)$ & 121 & $84(69 ; 61$ to 77$)$ \\
\hline $145-160$ & 241 & $147(61 ; 55$ to 67$)$ & 134 & $78(58 ; 50$ to 66$)$ \\
\hline $165-180$ & 153 & $98(64 ; 56$ to 71$)$ & 88 & $51(58 ; 48$ to 68$)$ \\
\hline $185-200$ & 85 & $59(69 ; 59$ to 79$)$ & 43 & $28(65 ; 50$ to 78$)$ \\
\hline$>200$ & 22 & $13(59 ; 38$ to 78$)$ & 12 & $7(58 ; 31$ to 83$)$ \\
\hline \multicolumn{5}{|l|}{ Diastolic: } \\
\hline $50-60$ & 59 & $52(88 ; 79$ to 95$)$ & 27 & $23(85 ; 70$ to 96$)$ \\
\hline $65-70$ & 124 & $92(74 ; 66$ to 81$)$ & 72 & $53(74 ; 63$ to 83$)$ \\
\hline $75-80$ & 251 & $172(69 ; 63$ to 74$)$ & 132 & $86(65 ; 57$ to 73$)$ \\
\hline $85-90$ & 224 & $148(66 ; 60$ to 72$)$ & 124 & $76(61 ; 53$ to 70$)$ \\
\hline $95-100$ & 126 & $82(65 ; 57$ to 73$)$ & 72 & $42(58 ; 47$ to 69$)$ \\
\hline $105-140$ & 46 & 27 (59; 44 to 72$)$ & 26 & $12(46 ; 28$ to 65$)$ \\
\hline
\end{tabular}

mortality (current infections and fractures) were entered as time dependent covariates.

The final model contained the following variables: type of residence (nursing home, home for the elderly, independent); score on the minimental state examination; health status according to the senior European (SENIEUR) criteria ${ }^{14}$ (that is, whether considered immunologically healthy based both on clinical information and laboratory data according to the SENIEUR protocol); presence of cachexia; dependence in activities of daily living (defined as not being able to eat, dress, or wash without help); history of cancer, diabetes mellitus, coronary heart disease, or heart failure; presence of oedema of the lower extremities, other circulatory diseases, chronic obstructive pulmonary disease, current infectious disease, or current fracture; use of potassium sparing diuretics or other diuretics, antihypertensive drugs, glycosides, antiarrhythmic drugs, or nitrates; packed cell volume; lymphocyte fraction; monocyte fraction; and serum concentrations of glucose, lactate dehydrogenase, sodium, chloride, urea, creatinine, and albumin. Using multiple imputation, we showed that possible bias caused by the missing measurements of blood pressure in $121(13 \%)$ participants was negligible (unpublished data).

\section{Results}

Most of the risk factors for mortality-such as a low score on the minimental state examination, dependency in activities of daily living (being unable to eat, wash, or dress without help), low serum concentrations of albumin, heart disease, and cancer-occurred more frequently in subjects with low diastolic blood pressure (table 1). Similar results were found when population characteristics were compared with systolic blood pressure. No differences between groups with different blood pressures were seen in the use of antihypertensive drugs.

For diastolic blood pressure crude 5 year all cause mortality decreased from 88\% (52/59) (95\% confidence interval $79 \%$ to $95 \%$ ) in those with diastolic blood pressures $<65 \mathrm{~mm} \mathrm{Hg}$ to $59 \%$ (27/46) (44\% to $72 \%)$ in those with diastolic blood pressures $>100 \mathrm{~mm} \mathrm{Hg}$. For systolic blood pressure, it decreased from $85 \%(95 / 112)(78 \%$ to $91 \%)$ in those with systolic blood pressures < $125 \mathrm{~mm} \mathrm{Hg}$ to $59 \%$ (13/22) $(38 \%$ to $78 \%$ ) in those with systolic blood pressures $>200 \mathrm{~mm} \mathrm{Hg}$. The results were similar when subjects using antihypertensive drugs were excluded (table 2).

When age and sex were adjusted for a significant inverse relation between blood pressure and mortality was observed, mainly due to an increase in the risk of mortality among those subjects with low diastolic pressure (diastolic blood pressure $\leqslant 60 \mathrm{~mm} \mathrm{Hg}$ ) or low systolic pressure ( $\leqslant 140 \mathrm{~mm} \mathrm{Hg}$ ) (figs 1 and 2). The risk of dying for a subject with low diastolic pressure was slightly diminished if an adjustment was made for the systolic blood pressure. The same was true if the risk of dying for a subject with low systolic pressure was adjusted for the diastolic pressure. None the less, the risk of dying among subjects with low blood pressure remained highly significant (highest $P$ value $=0.006$ )

The effect of high blood pressure was insignificant when all information that predicts mortality was adjusted for, including relevant comorbidity and the use of antihypertensive drugs, and the effect of low blood pressure on all cause mortality was reduced and no longer significant.

Similar results were seen when the mortality risks of men and women were analysed separately. However, because of the smaller numbers in each subgroup, for men the negative relation between blood pressure and

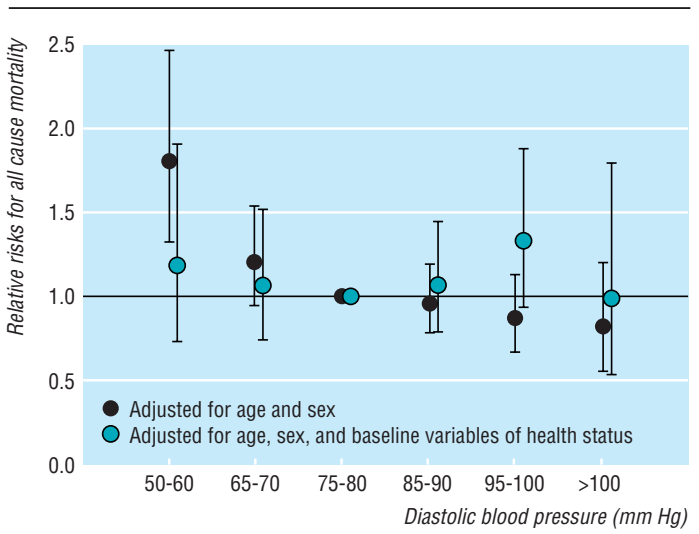

Fig 1 Relative risks for all cause mortality by diastolic blood pressure among 830 participants aged 85 and older

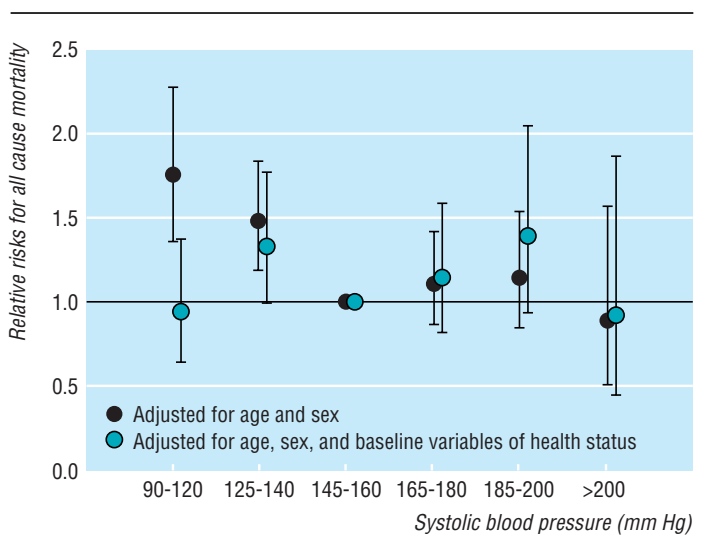

Fig 2 Relative risks for all cause mortality by systolic blood pressure among 835 participants aged 85 and older 
mortality from all causes adjusted for age remained strong only with diastolic blood pressure $(\mathrm{P}=0.0004)$ and was not significant for systolic blood pressure. For women the relation remained strong for systolic blood pressure $(\mathrm{P}=0.0002)$, and was only of borderline significance for diastolic blood pressure.

The fully adjusted relative risks in figure 1 are from a model that contains a large number of often related variables. The disappearance of a significant effect of low blood pressure, however, had already been seen in models containing only a few strong predictors of mortality, such as age, sex, type of residence, and concentrations of serum albumin. When the score on the minimental state examination was included in the model the relative risks of dying associated with low blood pressure decreased; this finding is similar to the results of a study done in a younger population. ${ }^{15}$ The disappearance of a significant effect was not due to the exclusion of subjects with missing data on the additional variables.

When data were analysed by cause of death and only age and sex were adjusted for, a significant inverse relation was observed between systolic blood pressure and death from other causes (that is, not cardiovascular causes, cancer, or infection). When health status was also adjusted for, this relation was no longer significant. However, a significant positive relation between higher diastolic blood pressure and an increased risk of dying from stroke and all cardiovascular causes was observed when adjusting for age, sex, and health status.

\section{Discussion}

In a population of 85 year olds we found an inverse relation between blood pressure and all cause mortality; this was consistent with the findings of a study of 85 year olds in Finland. ${ }^{78}$ Our data show, as have other studies, ${ }^{816}$ that poor health was more common in those with low blood pressure. It is unclear how much of this relation may be a result of poor health causing lower blood pressure (for example, by impairing cardiac function), or if it may have occurred because those who live to age 85 despite having high blood pressure are a highly selected group of healthy individuals. However, the inverse relation between blood pressure and all cause mortality disappeared after adjustment for health status.

No clear relation between blood pressure and all cause mortality was observed after frailty and poor health were adjusted for; this is in contrast to a study in a younger population with a mean age of 74 years. ${ }^{16} \mathrm{We}$ found a positive relation between diastolic blood pressure and mortality from all cardiovascular causes and mortality from stroke after adjusting for poor health. One possible explanation for this discrepancy between our study and others ${ }^{16}$ is the older age of our subjects. The little evidence that is available from clinical trials on hypertension in very elderly people ${ }^{12}$ indicates that there is a reduced effect of treatment as patients get older, possibly because the survival gained by treating hypertension becomes negligible when compared to the high overall mortality among very elderly people.

All cause mortality as a measure of outcome is not specific enough to detect the effect of differences in blood pressure. This would be consistent with our finding that after adjusting for health status there was a positive relation between diastolic blood pressure and
- Among community residents aged 85 and older there was a paradoxical inverse relation between blood pressure and all cause mortality: higher blood pressure was associated with lower mortality

- This inverse relation seems mainly to be due to higher mortality in those with low blood pressure; low blood pressure seems to be caused by poor health

- There was no longer a significant relation between blood pressure and all cause mortality after adjusting for health status. However, there was a positive relation between diastolic blood pressure and mortality from both cardiovascular causes and stroke

- Treating hypertension does not shorten life expectancy among elderly people aged 85 and older, and it might prevent disability from stroke

mortality from both cardiovascular causes and stroke. Another explanation might be that the variables measured in this study do not completely account for all aspects of poor health. For instance, many elderly people have had silent myocardial infarctions or have tumours that are undiagnosed and thus these types of diseases would not have been registered in this study. The last possible explanation is the inaccuracy caused by using a single, unstandardised measurement of blood pressure. This might bias the observed relative risks in the direction of unity. However, the fact that we observed a clear effect of low blood pressure on mortality indicates that the measurements are accurate enough to detect some effects.

In this study data were available on mortality, but not on the incidence of functional impairment or disability during the follow up period (for example, from non-lethal strokes or heart failure). We observed thathealth status being equal-mortality from stroke was associated with high blood pressure. Therefore, it is likely that the incidence of functional impairment and disability from stroke will be similarly associated with high blood pressure. Thus, people aged 85 or older may benefit from treatment for hypertension even if it is not useful in prolonging life, because it might prevent disability.

Whether it is wise to prescribe antihypertensive treatment to mildly hypertensive people older than 80 can only be determined by randomised clinical trials. In the meantime this epidemiological study indicates that treating hypertension does not decrease life expectancy and it might prevent functional impairment.

Contributors: $\mathrm{HCB}$ reviewed the literature, analysed the data interpreted results, wrote the paper, and is guarantor for the paper. GJI discussed core ideas, provided technical assistance with the Leiden 85 plus database, participated in the interpretation of the results and in writing the paper. SvB helped analyse the data (particularly the multiple imputations), interpreted the results, and participated in writing the paper. GJL supervised activities, discussed core ideas, participated in the interpretation of the results and in writing the paper. AM Lagaay was responsible for the baseline population survey of the Leiden 85 plus study and together with WCA van Beek she collected the baseline data. RGJ Westendorp provided assistance with the analysis of the data on the causes of death and commented on the manuscript.

Funding: This study was funded by the Netherlands Prevention Fund; the National Institutes of Health (grant number AG 06354); and the Dutch Ministry of Health, Welfare, and Sports.

Conflict of interest: None. 
1 Dahlöf B, Lindholm LH, Hansson L, Schersten B, Ekbom T, Wester PO, et al. Morbidity and mortality in the Swedish trial in old patients with hypertension (STOP-Hypertension). Lancet 1991;338:1281-5.

2 Amery A, Birkenhäger W, Brixko R, Bulpitt C, Clement D, Deruyttere M, et al. Efficacy of antihypertensive drug treatment according to age, sex, blood pressure and previous cardiovascular disease in patients over the blood pressure and previous car

3 SHEP Cooperative Research Group. Prevention of stroke by antihypertensive drug treatment in older persons with isolated systolic hypertension. JAMA 1991;265:3255-64.

4 Kostis JB, Davis BR, Cutler J, Grimm RH, Berge KG, Cohen JD, et al. Prevention of heart failure by antihypertensive drug treatment in older persons with isolated systolic hypertension. JAMA 1997;278:212-6.

5 Holme I, Waaler HT. Five-year mortality in the city of Bergen, Norway, according to age, sex and blood pressure. Acta Med Scand 1976;200:22939.

6 Heikinheimo RJ, Haavisto MV, Kaarela RH, Kanto AJ, Koivinen MJ, Rajala SA. Blood pressure in the very old. J Hypertens 1990;8:363-7.

7 Rajala S, Haavisto M, Heikinheimo R, Mattila K. Blood pressure and mortality in the very old. Lancet 1983;ii:520-1.

8 Mattila K. Haavisto M, Rajala S, Heikinheimo R. Blood pressure and five year survival in the very old. $B M J 1988: 296: 887-9$

9 Langer RD, Ganiats TG, Barret-Connor EL. Factors associated with paradoxical survival at higher blood pressure in the very old. Am J Epidemiol 1991;134:29-38
10 Izaks GJ, van Houwelingen HC, Schreuder GM, Ligthart GJ. The association between human leucocyte antigens (HLA) and mortality in community residents aged 85 and older. J Am Geriatr Soc 1997;45:56-60.

11 Lagaay AM, van der Meij JC, Hijmans W. Validation of medical history taking as part of a population based survey in subjects aged 85 and over. BMJ 1992;304:1091-2.

12 Folstein MF, Folstein SE, McHugh PR. "Mini-mental state": a practical method for grading the cognitive state of patients for the clinician. J Psychiatr Res 1975;12:189-98.

13 Weverling-Rijsburger AWE, Blauw GJ, Lagaay AM, Knook DL, Meiders $\mathrm{AE}$, Westendorp RGJ. Total cholesterol and risk of mortality in the oldest old. Lancet 1997;350:1119-23.

14 Ligthart GJ, Corberand JX, Fournier C, Galanaud P, Hijmans W, Kennes B, et al. Admission criteria for immunogerontological studies in man: the SENIEUR protocol. Mech Ageing Dev 1984;28:47-55.

15 Guo Z, Viitanen M, Winblad B. Low blood pressure and five-year mortality in a Stockholm cohort of the very old: possible confounding by cognitive impairment and other factors. Am J Public Health 1997;87:623-8.

16 Glynn RJ, Field TS, Rosner B, Hebert PR, Taylor JO, Hennekens CH. Evidence for a positive linear relation between blood pressure and mortality in elderly people. Lancet 1995;345:825-9.

(Accepted 12 February 1998)

\section{Lone atrial fibrillation in vigorously exercising middle aged men: case-control study}

Jouko Karjalainen, Urho M Kujala, Jaakko Kaprio, Seppo Sarna, Matti Viitasalo

Central Military Hospital, Box 50 00301 Helsinki, Finland

Jouko Karjalainen, internist

continued over BMJ 1998;316:1784-5

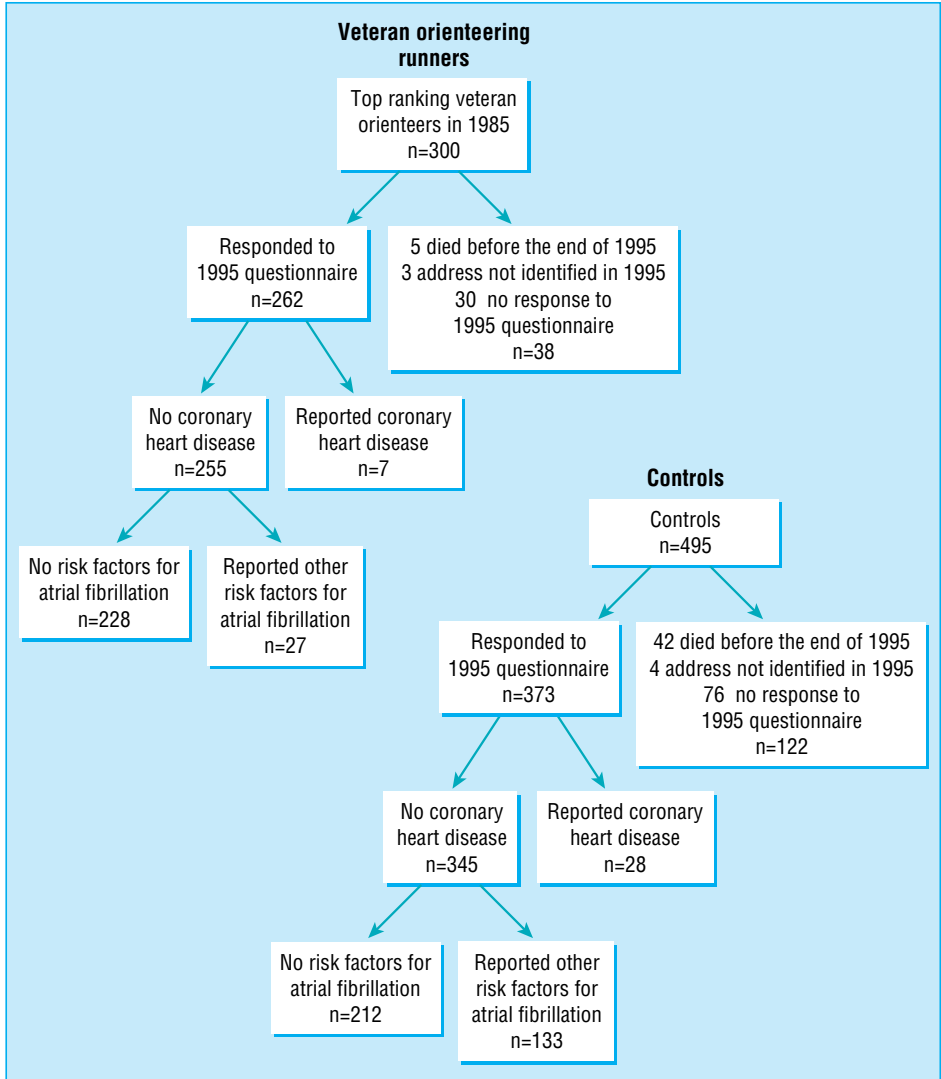

Flow chart of study. Other risk factors for atrial fibrillation were hypertension, myocardial or valve disease, diabetes, thyroid disorder, and severe obesity endurance sports. We therefore compared the prevalence of atrial fibrillation in middle aged men doing intense endurance training and men from the general population.

\section{Subjects, methods, and results}

We chose top level veteran orienteers to represent subjects doing long term vigorous exercise. A high position in the veteran ranking list is an indicator of years of intense training. We enrolled the 60 top ranked orienteers in 1984 from the race classes age 35-39 years, $40-44$ years, $45-49$ years, and $55-59$ years, a total of 300 runners. The 495 controls comprised all men aged 35-59 enrolled for an earlier study. ${ }^{2}$ At 20 years old these subjects had been completely healthy (fully fit for military service). Mean (SD) age at baseline was 47.5 (7.0) years in orienteers and $49.6(5.3)$ years in controls. Controls had responded in 1985 to a questionnaire which included items on physical activity and occurrence of various diseases. ${ }^{2}$

In 1995 we sent a similar questionnaire to the orienteers and controls but which contained an additional question on cardiac arrhythmias: "Has a doctor ever told you that you have atrial fibrillation or atrial flutter." Those who answered "yes" completed another detailed questionnaire on atrial fibrillation, and electrocardiograms and other data were obtained from their medical records to confirm the diagnosis. We excluded all subjects who reported known risk factors for atrial fibrillation. $^{3}$

Ninety per cent (262) of the orienteers and 83\% (373) of the controls responded to the questionnaire (figure). Compared with the general population orienteers had much lower mortality (1.7\% (95\% confidence interval 0.5 to $3.8 \%)$ v $8.5 \%(6.2 \%$ to $11.3 \%))$, lower reported coronary heart disease since 1985 (2.7\% (1.1 to $5.4 \%)$ v $7.5 \%(5.1 \%$ to $10.7 \%))$, and fewer risk factors for atrial fibrillation (figure). However, in men without known risk factors, lone atrial fibrillation had been 